\section{A difícil arte de falar com a boca cheia e a cabeça vazia}

\section{RESUMO}

0 presente texto responde aos pontos levantados por Carlos Gerbase no seu ensaio A digitalidade e a narrativa audiovisual, publicado na edição número 14 da Revista Famecos.

\section{ABSTRACT journal in its 14th issue. \\ PALAVRAS-CHAVE/KEY-WORDS \\ - Narrativa audiovisual (Audiovisual narrative) \\ - Tecnologia digital (Digital technology) \\ - Imagem (Image)}

This text answers some comments made by Carlos Gerbase in his essay Digitality and audiovisual narrative, published by this
André Parente

Professor ECO/UFRJ
"Um homem que não pensa por conta própria não pensa nada."

Oscar

Wilde

A nossa educação tem uma falha imperdoável: recriminam-se os que falam de boca cheia, mas não os que falam de cabeça vazia. Lendo o texto de Carlos Gerbase, "A digitalidade e narrativa audiovisual, uma relação complexa", ${ }^{1}$ ficase com a impressão de que ele é o sintoma de um novo tipo de problema que nos afeta, em parte devido a um produtivismo exacerbado, que consiste em falar cada vez mais de boca cheia e de cabeça vazia. Descrevemos, a seguir, os principais mal-entendidos do referido texto, com o intuito de esclarecer o leitor da Revista FAMECOS.

Em primeiro lugar, quanto à sua forma, utiliza-se um registro de comunicação inadequado a revistas acadêmicas, pois se procura preencher visíveis lacunas conceituais e inexperiências argumentativas por meio de agressões pessoais gratuitas. A partir de uma leitura tão apressada quanto enviesada de três textos publicados no livro Imagem-máquina, ${ }^{2}$ Gerbase se sente no direito de denunciar, como se se tratasse de um espetáculo de mágicos ilusionistas, todo um campo de pesquisa, o das novas tecnologias da imagem. Os autores Edmond Couchot, Arlindo Machado e André Parente ${ }^{3}$ são agredidos intelectualmente, não por suas idéias e suas obras, mas por suas supostas intenções mistificadoras ("caem na mesma generalização e na mesma adoração irracional"), especuladoras ("exageram as conclusões para que sejam 
espetaculares"), retrógradas ("quando fala de uma visão retrógrada, está falando dele mesmo"), reacionárias (defendem "não uma revolução libertadora, e sim uma contrarevolução"), confusas (fazem "confusões deliberadas"), incapazes (cometem "erros grosseiros").

Depois de muitas admoestações e acusações, os tais profetas impostores são condenados a terem se desviado dos ensinamentos da poética de Aristóteles. O leitor talvez consiga compreender Gerbase quando ele despacha os seus réus utilizando termos nada convencionais. Nesses momentos, ele revela-se de uma força bruta muito próxima das nossas necessidades mais elementares, como a fome, que ele cita, inclusive. Mas, quando ele argumenta, é a razão brutal que emerge insuportável.

Já em desespero de causa, ele conclui: "Nada de realmente 'revolucionário' apareceu", desde "a estrutura da narrativa que Aristóteles descreveu no século quarto (sic) a. C."!

Ou seja, aos novos processos técnicos de transformação das imagens causados pelas imagens digitais, imagens de sínteses, imagens interativas, imagens virtuais, comentados em Imagem-máquina, Gerbase opõe a estrutura da narrativa que Aristóteles descreveu há mais de 20 séculos!!!

Se, com o auxílio de toda a lógica de que dispomos, pudéssemos resumir a "idéia" de Gerbase, teríamos algo como: "Não há nada de novo sob o sol porque o sol é a razão de todas as coisas". "É realmente pensar abaixo da linha do intelecto!!!

Em segundo lugar, sobre o conteúdo, o movimento do texto de Gerbase é dominado por argumentos primários, de ordem moral, sentimentos confusos de alguém que se sente enganado.

É como se ele dissesse em altos brados: depois de tentar enganar os leitores com suas "profecias" e "mistificações", Parente, Couchot e Machado mostram um resultado decepcionante, pois "dão respostas vazias e quase desprovidas de interesse, pregam a revolução mas são sequer capazes de dar um único exemplo".

Aqui, neste ponto, é muito tentador dizermos que Gerbase age como um homem racional, que se torna colérico quando é preciso agir de acordo com os preceitos da razão. Mas é difícil agir dentro dos preceitos da razão se não se entende o que as pessoas estão dizendo à nossa volta. Só nos resta chorar, qual uma criança.

Esta é exatamente a situação de Gerbase, ou a de qualquer outra pessoa que queira escrever sobre algo sem se dispor a conhecer o assunto. Não é uma figura retórica não: como veremos adiante, Gerbase não sabe sequer diferenciar uma imagem digital de uma imagem de síntese.

Gerbase se queixa ainda do fato de os autores citados ignorarem o fazer cinematográfico, como se, para escrever sobre o que eles teorizaram, Parente, Couchot e Machado - que não apenas fizeram cinema todos os três, como também possuem mais livros publicados sobre o cinema do que todos os textos lidos sobre nova tecnologia por Gerbase - fossem obrigados a conhecer a teoria dos "3 Efes" do professor Damasceno Ferreira. Segundo Gerbase, "na visão do professor Damasceno Ferreira a humanidade corre atrás de 3 'efes': a fome, a 'foda' e o fasma”. É isso mesmo, citamos textualmente!

$\mathrm{Na}$ verdade, tudo o que Gerbase nos diz, baseado em sua experiência (mas em qual delas? a de jornalista, a de professor horista, a de escritor de novelas para a Internet, a de realizador de filmes juvenis, a de discípulo do professor Damasceno Ferreira?), é que o futuro não será muito diferente do passado, e que o pecado que cometemos - "o pecado dos comentadores da tecnologia digital" é a generalização dos processos de produção da imagem - será repetido muitas vezes. O que ele não pode imaginar é a alegria com que pecamos! De fato, as generalidades intelectuais são sempre interessantes, ao passo que 
as generalidades morais e empíricas são apenas o nome que os homens atribuem a seus erros.

Agora, vejamos alguns dos pontos críticos do texto apresentado por Gerbase.

\section{Ultrapassando os limites do bom senso}

Uma frase de André Parente, em sua introdução ao livro Imagem-máquina, deixou Gerbase possesso. A frase diz o seguinte:

"Não podemos negar que os processos eletrônicos digitais provocarão uma transformação geral de todas as fases de elaboração de uma imagem".

Segundo Gerbase, esta frase "parece ultrapassar os limites do bom senso". Sabemos que muitos daqueles que são incapazes de aprender sequer a ler um texto fazem carreira no ensino: eis onde nos levou o entusiasmo pela educação. É muito precisamente este o caso de Gerbase, com a sua mais completa falta de senso.

Sim, os processos digitais provocaram uma transformação geral de todas as fases de produção da imagem. Sim, a reprodutibilidade técnica digital é um dado irreversível. Sim, a fotografia, o cinema, o vídeo e a televisão tendem ao digital. Sim, a cada dia que passa, novas e extraordinárias máquinas de visão são colocadas à disposição do homem: telescópios de óticas ativas, microscópios de varredura por tunelamento, satélites de sensoramento e tomógrafos computadorizados são máquinas espetaculares, todas elas computadorizadas e digitais, capazes de nos fazer ver o improvável.

Sim, a imagem já não é mais vista com a mesma predisposição: como olhar para uma foto da mesma forma, se sabemos que ela pode ter sido transformada em cada um de seus pontos? Sim, hoje, o processo de produção de uma imagem já não se faz apenas no momento de sua captação (filmagem, gravação, etc.). Isto quer dizer que o processo de edição se tornou um momento-chave na produção da imagem. Na edição, seja de uma imagem fotográfica, cinematográfica, videográfica ou televisiva, pode-se reenquadrar a imagem, mudar a forma, a textura e a cor de seus objetos, o movimento e demais parâmetros da imagem. Para muitos, é na edição que várias imagens ou camadas vão se juntar para compor uma só imagem. E o que dizer da transmissão, da estocagem, da indexação e da distribuição das imagens? Sim, acreditamos que qualquer fotógrafo, cineasta ou profissional do audiovisual reconhecerá que as tecnologias digitais transformaram radicalmente a nossa forma de pensar, produzir, editar, estocar, transmitir e ver uma imagem.

\section{A diferença desapercebida}

Segundo Edmond Couchot, que faz uma distinção entre as técnicas figurativas ópticas e as técnicas figurativas computacionais, a imagem de síntese é virtual, pois é fruto de linguagem matemática, cálculos numéricos, algoritmos, e não da captação fotomecânica de uma realidade física. Segundo Gerbase,

\section{"quem já viu uma criança de três anos desenhando num computador terá dificuldade de perceber onde, neste processo de produção da imagem, está o seu caráter acentuadamente teórico ou argumentado".}

Gerbase não percebeu a diferença, tão claramente apontada por Couchot, porque simplesmente não sabe a diferença entre uma imagem digital e uma imagem de síntese. Ora, a pintura eletrônica não produz uma imagem de síntese, mas apenas uma imagem digital. Toda imagem de síntese é digital, mas não o contrário.

Uma imagem fotográfica 
digitalizada, uma pintura digitalizada não é fruto de nenhum processo de figuração propriamente computacional. Uma imagem de síntese é fruto de cálculos matemáticos, equações, como os fractais. Estas imagens são representações de uma matemática computacional, que busca traduzir os fenômenos através de equações que possam simulá-los. A simulação computacional é, hoje, uma das mais importantes ferramentas da ciência, da tecnologia e da arte. Podemos mesmo dizer que, hoje, o homem não dispõe mais apenas das narrativas e das lógicas para representar o mundo, mas agora também da simulação computacional. Pode-se, através da simulação computacional, mas não da imagem digital, criar e testar modelos virtuais, sejam eles de realidades teóricas ou físicas, matemáticas ou biológicas, sociais ou naturais.

Somos muito críticos em relação a Couchot, mas apenas porque ele procurou mostrar que imagem de síntese deixa de ser representação porque deixa de representar uma realidade visível preexistente. ${ }^{5}$

seja, Couchot confunde representação e reprodução. Uma imagem de síntese pode não representar uma realidade física preexistente do ponto de vista do processo de reprodução de suas ondas eletromagnéticas, tal como ocorre em uma imagem fotomecânica. Mas não é porque uma imagem não copia a realidade física preexistente, do ponto de vista da visão, que ela não representa, às vezes melhor do que qualquer modelo de figuração fotomecânico, uma realidade. A realidade modelada pela imagem de síntese só existe enquanto realidade simulada, mas ela se substitui perfeitamente aos fenômenos ou a experiência reais. Não é à toa que a imagem de síntese é um instrumento aperfeiçoado de representação de muitas realidades que não podemos ver ou compreender com a nossa visão. Mas, se a imagem de síntese não representasse realidade alguma, ela não seria um importante instrumento científico e tecnológico de simulação e modelagem de situações e objetos possíveis. Podemos, para falar com maior rigor, dizer que a imagem de síntese não representa mais a experiência sensível, mas a experiência possível.

\section{A câmera escura da ignorância}

O professor Gerbase imputa a Parente a idéia de que ele estaria pregando a revolução, ou seja, o fim da câmera escura - segundo ele, implícita na frase supracitada, que afirma que os processos eletrônicos digitais provocarão uma transformação geral de todas as fases de elaboração de uma imagem. Em momento algum desta frase e de seu texto, Os paradoxos da imagem-máquina, Parente deixou transparecer um tal absurdo. Não é Parente, mas Jean Baudrillard e Paul Virilio que sustentam a idéia de que a digitalização e a virtualização da imagem significa, antes de tudo, um processo de instrumentalização da imagem, um processo por meio do qual a imagem será, cada vez mais, imagem de ninguém, feita por ninguém, vista por ninguém, mas que tende a substituir os nossos referentes sociais e subjetivos. É esta visão, esta estética da desaparição, que tende a fazer desaparecer não apenas a câmera escura, mas também o mundo ele mesmo.

Ao invés de sustentar essa visão "desesperada", preferimos sustentar a idéia de que a visualização computacional inaugurou uma era pós-kantiana, que perturba as três principais instâncias da representação científica: o mundo, o cérebro e as condições, práticas e teóricas, da experiência que lhes coloca em relação. Que nome dar a esta nova imagem, a esta nova representação, se ela abandona sua antiga função fenomenológica, uma vez que não é mais determinada pelos horizontes espaço-temporais de nossa experiência sensível? Que cor atribuir a 
um sinal recebido em faixas de ondas exteriores àquelas do espectro visível? Como qualificar o olhar quando ele faz face a uma imagem fractal, que se situa em uma zona intermediária entre o sensível e o inteligível? Quem vê, um outro orgão que o olho? Quem calcula, um outro orgão que o cérebro? Como chamar de imagem esta dimensão flutuante, entre o sensível e o inteligível? Sim, sem dúvida, entramos no campo da experiência do possível e do virtual.

É verdade que a modelização e a simulação computacional são, epistemolo gicamente falando, uma reviravolta para a ciência. Não apenas todas as disciplinas as utilizam, como também fazem apelo a toda uma imagerie que transforma radicalmente o aparato cognitivo dos cientistas, uma vez que diz respeito à representação da realidade, à maneira de tratar a informação, ao modo de análise das imagens, ao reconhecimento dos padrões dos sinais, enfim, à construção de seus modelos e reproduções.

Gerbase não termina seu lamentável texto sem tentar sujar a imagem de um dos maiores teóricos da imagem-técnica. Tratase de Arlindo Machado. Criticando Machado e a sua idéia de que a imagem do vídeo é a verdadeira imagem em movimento, ao contrário da imagem do cinema, onde o movimento é ilusório, ele o ataca de forma deselegante, mas com aquela razão brutal que lhe é própria: "Machado faz uma confusão (deliberada?)". O que quer dizer isto? Ou então: "as respostas de Machado tendem a ser vazias e quase desprovidas de interesse, à medida que prefere (como muitos outros acadêmicos) ignorar a concretude do espetáculo audiovisual".

A crítica a Machado é apenas uma forma de dizer que estes autores fazem confusões deliberadas como modo de enganar os seus leitores sobre os verdadeiros fatos. Não é chamá-los de desonesto? De que adianta saber que a imagem cinematográfica é movimento se não nos damos ao tempo da visão? Afinal de contas, é essa a grande crítica que nos une a todos: que as imagens não têm mais tempo. É esta, inclusive, a crítica de Paul Virilio, de que a imagem instrumental elimina a distância (suposta por toda câmera escura), de tempo, que separava a imagem do espectador. $E$ quando isto ocorre, elimina-se a interação, a relação, o referente, a imagem e tudo o mais.

Criticar sem ler é como querer olhar sem enxergar, é como querer ver sem interagir. Eis aí como a câmera escura obscurece. Não é à toa que Nietzsche, Marx, Freud, cada um a seu modo, em função dos três tipos de inconscientes que fundaram, criticaram a pretensa objetividade da câmera escura, dispositivo que eles compararam ao da razão, com sua face clara e sua face escura. ${ }^{6}$

Segundo Gerbase, este seu texto não foi feito para ser publicado, mas sim como trabalho final para um curso do professor Juremir Machado da Silva. O professor Juremir, por sua vez, disse que publicou o texto por uma questão de liberdade de expressão. Mas, francamente, liberdade de expressão é outra coisa. Cá entre nós, a liberdade de agressão acaba de ser criada pela FAMECOS.

Para terminar, deixo aqui uma pequena bibliografia, em várias línguas, para não haver desculpas. Nela, o leitor encontrará discussões apaixonadas e muitos e muitos exemplos, que vão da câmara escura à arte eletrônica, passando pelo cinema cibernético e pelo vídeo instalação. Mas o maior de todos os exemplos é o do trabalho mesmo dos pesquisadores. Pois pesquisar é um trabalho específico, tanto quanto fazer cinema, que exige esforço e, muitas vezes, generosidade. Ou pelo menos um respeito para com o outro .

Notas

1 Cf. FAMECOS, n. 14, abril de 2001. 
20 livro Imagem-máquina. A era das tecnologias do virtual. (Rio de Janeiro: Ed. 34, 1993), que se encontra em sua $3^{3}$ edição, não é uma somatória, mas possui uma multiplicidade de pontos de vistas, por vezes antagônicos.

3 Tendo em vista que não me reconheço de forma alguma nas descrições confusas de Gerbase, resolvi falar de mim mesmo na terceira pessoa.

4 Segundo Gerbase, a razão de todas as coisas é a teoria dos 3 "Efes" do prof. Damasceno Ferreira: "A fome, a foda e 0 fasma". Cf. p. 98.

$5 \quad$ Em alguns de nossos artigos, temos combatido essa visão evolucionista das coisas. Cf. "A imagem virtual, auto-referente". In: 0 virtual e o hipertextual. Rio de Janeiro: Pazulin, 1999. pp. 14-27. De um lado, teríamos os modelos óticos de figuração, que tiveram origem com a perspectiva centro-linear Renascentista, com seus perspectivadores, e em particular a câmara obscura, protótipo dos modelos fotomecânicos. Esses modelos produzem imagens (pintura, fotografia, cinema e vídeo) como duplo do real, que dependem de uma fé perceptiva em uma aderência ao mundo real como lugar das coisas e dos fenômenos. A conquista do instantâneo fotográfico, do movimento cinematográfico e da simultaneidade da transmissão televisiva operaram uma aproximação cada vez maior do real e da imagem como seu duplo. Do outro lado, teríamos os modelos numéricos e digitais, responsáveis pelas imagens de síntese, imagens e realidades virtuais, autoreferentes. Se alguma coisa preexiste à imagem de síntese é o programa, isto é, números: "a imagem não mais representa o real, ela 0 simula". A partir dessa ruptura dos modelos de figuração, Couchot tira uma série de conseqüências. A mais importante delas, afirma que, com a imagem virtual "não se trata mais de figurar o visível: trata-se de figurar aquilo que é modelizável". Ou melhor, a imagem não é mais a representação do visível, tendo em vista que ela não é mais a representação do real preexistente. Couchot não estaria confundindo representação e reprodução? Se, por um lado, a imagem de síntese não reproduz o real fenomênico, por outro lado, não se pode com isso querer deduzir que ela não seria mais da ordem da representação. Mesmo porque a maior parte da produção de imagens de síntese satisfaz um desejo de representação do visível, e, mais profundamente, das significações pressupostas do real.

6 Cf. a este respeito o belíssimo livro de Sarah Kofman. Camera obscura de l'idéologie. Paris: Galilée, 1973.

\section{Referências}

ARISTARCO, GUIDO e TEREZA. II nuovo mundo dell'immagine elletronica. Roma: Dédalo, 1985.

AUMONT, J. L'oeil interminable. Paris: Séguier, 1989.

BEAU, F. Dubois, Ph. \& Leblanc, G. Cinéma et dernières technologies. Paris: INA, 2000.

BELLOUR, R. (Org.) Passages de l' image. Paris: Centre Georges Pompidou, 1990.

. L'entre-images. Paris: Ed. De La Différence, 1990.

BETTETINI, G. La simulazione visiva. Inganno, finzione, poesia, computer graphics. Milano: Bompiani, 1991.

. La Simulazione visiva. Milan: Bompiani, 1991.

CANTOR, G. N. Optics after Newton. Manchester: Manchester University Press, 1983.

CAUQUELIN, A. L'invention du paysage. Paris: Plon, 1989.

COMMENT, Bernard. Le XIXème siècle des panoramas. Paris: Adam Biro, 1993.

COUCHOT, E. Images: de l'optique au numérique. Paris: Hermes, 1988.

CRARY, J. The technics of observer. Cambridge: MIT Press, 1990.

DAGOGNET, F. Etienne-Jules Marey. Paris: Hazan, 1987.

DAMISCH, H. L'origine de la perspective. Paris: Flammarion, 1987.

DIDI-HUBERMAN, G. Devant l'image. Paris: Minuit, 1990. . Invention de l'hystérie. Paris: Macula, 1982.

DUBOIS, Ph. "La question du panorama: entre photo-graphie et cinéma". IN: La Revue de la Cinémathèque, $\mathrm{n}^{\circ} 4$, Paris: 1995.

HEIM, M. The metaphysic of virtual reality. Oxford: Oxford Press, 1993. 
HENDERSEN, L. D. The fourth dimension and non-euclidien geometry in modern art. Princenton: Princenton University Press, 1983.

KALAWSKY, R. S. The Science Of Virtual Reality. Wokingham, Addison-Wesley, 1993.

LAUREL, B. (org.) Art of human computer interface design. Reading, Massachusets: Addison-Wesley, 1990.

LINDBERG, D. C. Theories of vision from al-kindi to kepler. Chicago, University of Chicago Press, 1976.

MACHADO, A. A ilusão especular. Introdução à fotografia. São Paulo: Brasiliense, 1984.

. A arte do vídeo. São Paulo: Brasiliense, 1988.

. Máquina e imaginário. São Paulo, Edusp, 1993.

O quarto iconoclasmo. Rio de Janeiro: Contra-capa,

2001

. Pré-cinema e pós-cinema. Campinas: Papirus, 1997.

MANDELBROT, B. The fractal geometry of nature. New York: Freeman, 1977.

MARIN, L. Des pouvoirs de l'image. Paris: Seuil, 1993.

PARENTE, A. e NAGIB, L. Ozu: o extraordinário cineasta do cotidiano. São Paulo: Marco Zero, 1990.

PARENTE, A. Narrativa e modernidade. 0 cinema nãonarrativo do pós-guerra. Campinas: Papirus, 2000.

"La transparence de l'image electronique et ses courts-circuits". In: Nuovi media e sperimentazione d'artista. Napoli: Edizioni Scientifiche Italiane, 1994.

"Le cinéma de la pensée ou le virtuel en tant que jamais vu". In: Gilles Deleuze, une vie philosophique. Paris: Institut Synthélabo, 1998.

Imagem-máquina. A era das tecnologias do virtual. Rio de Janeiro: Editora 34, 1993.

0 virtual e 0 hipertextual. Rio de Janeiro, Editora Pazulin, 1999.
Sobre o cinema do simulacro. Cinema existencial, cinema estrutural e cinema brasileiro contemporâneo. Rio de Janeiro: Editora Pazulin, 1998.

POPPER, F. Art of the eletronic age. New York: Herry N. Abrams, Inc., Publishers, 1993.

QUEAU, P. Le virtuel. Vertus et vertiges. Paris: Champ Vallon/ Ina, 1993.

RHEINGOLD, H. Virtual reality. London: Seccer And Warburg, 1991.

SIMON, G. Le regard, l'être et l' apparence dans l'optique de l'antiquité. Paris: Seuil, 1988.

"Technimages (Les)". Revue d'esthétique 25, 1994. Número organizado por Anne Cauquelin.

VIRILIO, Paul. A máquina de visão. Rio De Janeiro: José Olympio, 1994.

YOUNGBLOOD, G. Expanded cinema. New York: Dutton, 